\title{
Refinement of the Quebec decision rule for radiography in shoulder dislocation
}

\author{
Marcel Émond, MD, MSc; ${ }^{* \dagger}$ Natalie Le Sage, MD, MSc; ${ }^{* \dagger}$ André Lavoie, $\mathrm{PhD}{ }^{* \dagger}{ }^{*}$ Lynne Moore, MSc ${ }^{* \dagger}$
}

\begin{abstract}
Objective: We prospectively derived a clinical decision rule to guide pre- and postreduction radiography for emergency department (ED) patients with anterior glenohumeral dislocation.

Methods: This prospective cohort derivation study took place at 4 university-affiliated EDs over a 3-year period and enrolled consenting patients with anterior glenohumeral dislocation who were 18 years of age or older. We compared patients with a clinically important fracture-dislocation with those who had an uncomplicated dislocation to provide the clinical decision rule components using recursive partitioning. The final rule involved age, mechanism, prior dislocation and humeral ecchymosis.

Results: A total of 222 patients were included in the study. Forty (18.0\%) had clinically important fracture-dislocation. A clinical decision rule using 4 factors reached a sensitivity of $100 \%(95 \%$ confidence interval [CI] $89.4 \%-100 \%)$, a specificity of $34.2 \%(95 \% \mathrm{Cl} 27.7 \%-41.2 \%)$, a negative predictive value of $99.2 \%(95 \% \mathrm{Cl} 92.8 \%-99.9 \%)$ and a negative likelihood ratio of $0.04(95 \% \mathrm{Cl}$ $0.002-0.27$ ). Patients younger than 40 years are at high risk for clinically important fracturedislocation only if the mechanism of injury involves substantial force (i.e., a fall greater than their own height, a sport injury, an assault or a motor vehicle collision). Patients 40 years of age or older are at high risk only in the presence of humeral ecchymosis or after their first dislocation. Projected use of the rule would reduce the absolute number of prereduction radiographs by $27.9 \%$ and of postreduction by $81.9 \%$.

Conclusion: The Quebec shoulder dislocation rule for patients with acute anterior glenohumeral dislocation holds promise to reduce unnecessary imaging, pending validation.
\end{abstract}

Keywords: anterior shoulder dislocation, emergency medicine, clinical decision rules, shoulder fractures

\section{RÉSUMÉ}

Objectif : Notre étude visait à établir de façon prospective une règle de décision clinique afin de guider le recours aux radiographies précédant et suivant la réduction chez les patients se présentant à l'urgence avec une luxation glénohumérale antérieure.

Méthode : Cette étude de dérivation sur une cohorte prospective s'est déroulée sur une période de 3 ans, dans 4 services d'urgence d'hôpitaux universitaires. Nous avons inscrit des patients consentants de 18 ans ou plus qui présentaient une luxation glénohumérale antérieure. Nous avons comparé les patients ayant une luxation ou une fracture cliniquement importante avec ceux qui avaient une luxation sans complication en vue d'établir les critères d'une règle de décision clinique

From the *Centre Hospitalier Affilié, Universitaire de Québec, Québec City, Que., the †Department of Social and Preventative Medicine, Laval Univeristy, Québec City, Que., and the ¥Department of Family Medicine, Emergency Medicine Section, Laval University, Québec City, Que.

This article has been peer reviewed.

CJEM 2009;11(1):36-43 
en utilisant le partitionnement récursif. Les critères de la règle définitive étaient l'âge, le mécanisme de blessure, les antécédents de luxation et une ecchymose au niveau de l'humérus.

Résultats : L'étude comptait 222 patients. Quarante $(18,0 \%)$ présentaient une fracture ou une luxation cliniquement importante. La règle de décision clinique fondée sur 4 facteurs avait une sensibilité de $100 \%$ [intervalle de confiance (IC) à $95 \%$ de 89,4 à $100 \%$ ), une spécificité de $34,2 \%$ (IC à $95 \%$ de 27,7 à 41,2\%), une valeur prédictive négative de 99,2 \% (IC à $95 \%$ de 92,8 à $99,9 \%$ ) et un rapport de vraisemblance négatif de 0,04 (IC à $95 \%$ de 0,002 à 0,27). Les patients de moins de 40 ans présentent un risque élevé de fracture ou de luxation cliniquement importante seulement si le mécanisme de blessure implique une force d'impact importante (c'est-à-dire chute d'une hauteur supérieure à celle de la victime, blessure liée à un sport, agression ou accident automobile). Les patients de 40 ans ou plus sont exposés à un risque élevé seulement en présence d'une ecchymose au niveau de l'humérus ou après une première luxation. Les projections quant à l'utilisation de cette règle permettent de croire qu'on réduirait le nombre absolu de radiographies pré-réduction de $27,9 \%$ et celui des radiographies post-réduction de 81,9\%.

Conclusion : La règle concernant les luxations d'épaule appliquée au Québec pour les patients présentant une luxation glénohumérale antérieure aiguë est prometteuse. Elle pourrait en effet réduire le recours à l'imagerie, dans l'attente de sa validation.

\section{Introduction}

Glenohumeral dislocation is an important cause of shoulder injuries seen in the emergency department $(\mathrm{ED})^{1,2}$ and is the most frequent type of dislocation reduced by emergency physicians (EPs). ${ }^{3}$ Prereduction radiography of the shoulder is generally advocated to confirm the diagnosis and to identify any associated fracture. ${ }^{3-5}$ However, this practice has been questioned recently. ${ }^{6-10}$

Some investigators have suggested that prereduction radiography should be used only when diagnosis is uncertain or when an associated fracture is suspected. ${ }^{8,11}$ Until recently, no study had examined the presence of risk factors for concomitant fractures in anterior shoulder dislocations. We have previously shown that clinical gestalt has a sensitivity of only $77.3 \%$ for fracture-dislocation. ${ }^{6}$ In this retrospective derivation study, we identified 3 different factors that were predictive of a fracture-dislocation: 1) patient age of 40 years or older, 2) whether it is the patient's first episode of dislocation, and 3) the specific blunt mechanism of injury. ${ }^{6}$ Recently, Hendey and colleagues ${ }^{9}$ suggested that prereduction radiography was unnecessary in patients with recurrent dislocations. Guidelines for efficient prereduction radiography would impact the use of postreduction radiography, as studies have shown that postreduction radiography rarely identifies significant clinical lesions and may not be needed. ${ }^{7,812}$

Supplementing physician judgment with a decision rule that identifies patients unlikely to harbour a clinically significant fracture-dislocation could substantially reduce the use of imaging following this common injury, resulting in better resource allocation and shorter lengths of stay in the ED. The aims of our study were to refine previously derived factors associated with clinically important fractures in ED patients with anterior glenohumeral dislocation and to develop a clinical decision rule for radiography in such patients.

\section{Methods}

\section{Study design and setting}

We conducted a prospective derivation cohort study at 4 university-affiliated EDs in the greater Québec City area between November 2001 and December 2004. All 4 institutional review boards approved the study. Subjects provided written informed consent before being discharged from the ED.

\section{Selection of participants}

Consecutive patients with acute glenohumeral dislocations were enrolled provided they were at least 18 years of age and able to give informed consent. In cases of patients who had multiple visits during the study period, only the first episode of shoulder dislocation was included in order to preserve statistical independence. Patients with an initial Glasgow Coma Scale score of 13 or less were excluded, as were patients whose radiographs or ED charts could not be retrieved.

\section{Data collection and processing}

Patients were assessed by EPs before prereduction radiographs were obtained. A standardized clinical worksheet was used by EPs to record all clinical, demographic and radiologic data for the study. Patients were enrolled by the EP on duty after the shoulder reduction had been performed. Research personnel subsequently retrieved additional data from the medical record and conducted 
structured follow-up interviews by telephone after 1 week, 1 month and 3 months to identify any fracture-dislocations that were initially missed but subsequently diagnosed. The mechanism of injury was classified into 8 categories using both EP notes and telephone interviews: 1) a fall from patient's own height or less, 2) a fall from more than own height but less than 1 flight of stairs, 3) a fall from 1 flight of stairs or more, 4) a sport activity involving physical contact (e.g., hockey), 5) a sport activity involving speed (e.g., alpine skiing), 6) a fight or assault, 7) a motor vehicle collision, and 8) an atraumatic mechanism. Clinical parameters related to findings on shoulder examination were systematically recorded by the enrolling EP. All potential predictor variables were prespecified based on a review of existing literature by 2 of the authors (M.E. and N.L.).

\section{Outcome measure}

The primary outcome was a clinically important fracturedislocation, defined as a shoulder fracture associated with an anterior glenohumeral dislocation in which special care was needed during reduction to prevent distraction of previously minimally displaced segments, or in which surgical fixation of segments by orthopedics was needed. These criteria were derived from a review of the literature and by consensus among the investigators. Examples included fractures of the humeral head or neck, greater tuberosity or glenoid. A Hill-Sachs lesion was deemed not to be a clinically important fracture-dislocation for our study, as these fractures do not affect the ED management. ${ }^{13,14}$ Standard plain shoulder radiographs including the Neer's view were obtained on all subjects both prereduction and postreduction. Radiographic interpretations were based on the final radiologist's reports. The mean ED length of time to get a prereduction radiograph was calculated from the EP encounter time to the moment the radiograph was taken.

\section{Primary data analysis}

Baseline analyses were done to compare study subjects with eligible patients who were missed for inclusion in the study. Univariate analyses were conducted for each potential predictive factor with SAS software 9.0 (SAS Institute, Inc.). Statistical significance was set at $p<0.05$. Subsequently, a recursive partitioning (classification and regression tree $[\mathrm{CART}]$ ) analysis was performed according to the technique previously described by Breiman. ${ }^{15}$ CART is a nonparametric method of analysis used to classify observations. It is based on a large number of possible predictive variables and is well suited to identify complex, higher level interactions among variables.
We created CART models with our predictor variables to classify subjects according to the main outcome using Answertree 3.1 (SPSS Inc.). For all CART analyses, we used unweighted variables, 10-fold cross-validation, Gini splitting rules, a maximum tree depth of 5 and a minimum change in impurity greater than 0.001 . Pruning was elaborated with a minimum risk analysis. ${ }^{15}$ To maximize sensitivity, a misclassification cost of 10 to 1 was attributed to false negative prediction. Predictor selection was performed to achieve maximum sensitivity. Investigators reviewed each derived rule for clinical relevance. Nodes with small numbers of patients were aggregated and recursive partitioning was reinstituted to simplify the branch points. This modification, although not previously described, makes clinical sense and lowers the chance of selecting a suboptimal splitting variable when partitioning groups with smaller sample sizes were involved. The simplest, most specific prediction rule that met the sensitivity objective of greater than $98 \%$ (based on the derivation phase ${ }^{6}$ ) was chosen. Sensitivity, specificity, predictive values and likelihood ratios values along with their $95 \%$ confidence intervals (CIs) were calculated. The total sample size estimation was 210 patients based on a sensitivity of $98 \%$, a specificity of $50 \%$, a prevalence of $15 \%$ and using an $\alpha$ of 0.05 and $\beta$ of $0.20 .{ }^{16}$

\section{Results}

\section{Characteristics of study subjects}

A total of 377 patients with acute anterior shoulder dislocation were seen in the 4 EDs during the recruitment period. Of these, 98 (26.0\%) were missed for inclusion in the study and $57(15.1 \%)$ refused or were ineligible, leaving a study population of $222(58.9 \%)$ patients. Table 1 shows characteristics of the study patients compared with the eligible missed patients, who were slightly older. Univariate analysis stratified by recruiting site showed no statistically significant difference between the included and missed eligible groups on any predictor variable or the primary outcome of clinically important fracture-dislocations (data not shown). All 222 patients enrolled had pre- and postreduction radiography by protocol in this prospective study. A total of $183(82.4 \%)$ patients were contacted by telephone at least once for follow-up and none had a new clinically important fracture diagnosed following the index ED visit. All patients enrolled in the study had a Glasgow Coma Scale score of 15 .

\section{Main results}

Of the 222 subjects in the study population, 40 (18.0\%) 
were deemed to have a clinically important fracturedislocation. Thirty-eight of these were identified on prereduction radiography. An additional 6 fractures were identified on the postreduction film. Two of these were clinically significant (Bankart 1, greater tuberosity 1), both in patients over the age of 40 with no prior dislocation. In each of these 2 cases, the EP was also uncertain of the success of the reduction.

Univariate analyses of potential predictive factors are shown in Table 2 . Patients with clinically important fracturedislocations were significantly older (mean age 59.0, standard deviation [SD] 20.4, yr) than patients with an uncomplicated dislocation (39.7, SD 20.2, yr). The other factors on univariate analysis found to be strongly associated with a clinically important fracture-dislocation were age greater than 40 years, female sex, no prior dislocation, an atraumatic mechanism of injury, fall from standing height or less and the presence of humeral ecchymosis.

The results of the multivariate recursive partitioning analysis are shown in Figure 1. Three discrete combinations

Table 1. Characteristics of the 222 shoulder dislocation study patients and the subgroup of 98 eligible patients who were missed for inclusion in the study

\begin{tabular}{|c|c|c|c|c|}
\hline \multirow{3}{*}{$\begin{array}{l}\text { Characteristic } \\
\text { Age } \geq 40 \mathrm{yr}\end{array}$} & \multicolumn{4}{|c|}{ Group, no. (\%) } \\
\hline & \multicolumn{2}{|c|}{$\begin{array}{l}\text { Study } \\
\text { patients }\end{array}$} & \multicolumn{2}{|c|}{$\begin{array}{l}\text { Patients } \\
\text { missed }\end{array}$} \\
\hline & 110 & $(49.5)$ & 59 & $(60.2)$ \\
\hline Male sex & 156 & $(70.3)$ & 69 & (70.4) \\
\hline Alcohol intoxication & 6 & $(8.1)$ & 26 & (12.3) \\
\hline \multicolumn{5}{|l|}{ Injury mechanism* } \\
\hline Atraumatic & 42 & (19.4) & 16 & $(19.2)$ \\
\hline \multicolumn{5}{|l|}{ Falls } \\
\hline Patientís own height & 64 & $(29.5)$ & 41 & $(49.4)$ \\
\hline$<1$ flight of stairs & 25 & $(11.5)$ & 3 & (3.7) \\
\hline$>1$ flight of stairs & 3 & $(1.4)$ & 0 & \\
\hline \multicolumn{5}{|l|}{ Sports activity } \\
\hline With speed & 25 & $(11.5)$ & 14 & $(16.9)$ \\
\hline With contact & 47 & $(21.6)$ & 5 & $(6.0)$ \\
\hline Fight or assault & 4 & $(1.8)$ & 2 & (2.4) \\
\hline MVC & 12 & $(5.4)$ & 2 & (2.4) \\
\hline Type of associated fracture & 53 & $(23.9)$ & 25 & $(25.5)$ \\
\hline Hill-Sachs & 13 & $(5.8)$ & 3 & (3.2) \\
\hline Bankart & 3 & $(1.4)$ & 2 & (2.1) \\
\hline $\begin{array}{l}\text { Humeral head or surgical } \\
\text { neck }\end{array}$ & 7 & $(3.2)$ & 3 & (3.2) \\
\hline Greater or lesser tuberosity & 23 & $(10.4)$ & 14 & $(14.2)$ \\
\hline Qualified as comminuted & 7 & $(3.2)$ & 3 & (3.2) \\
\hline $\begin{array}{l}\text { Clinically important fracture- } \\
\text { dislocation }\end{array}$ & 40 & $(18.0)$ & 22 & $(22.4)$ \\
\hline $\begin{array}{l}\text { MVC = motor vehicle collision. } \\
{ }^{*} \text { Mechanism of injury could not be dete } \\
15 \text { eligible but missed patients. }\end{array}$ & & & & w for \\
\hline
\end{tabular}

of factors identified all 40 clinically significant fracturedislocations: 1) aged 40 years or older AND humeral ecchymosis, 2) aged 40 years or older AND first episode of dislocation, or 3) younger than 40 years AND injury mechanism other than a fall from standing height or an atraumatic injury. When EPs were certain of appropriate reduction, the postreduction radiographs confirmed the anatomical position of the shoulder in all cases.

We then constructed a clinical decision rule, which is represented in Figure 2. Prereduction radiography would be performed based on the 3 groups above. Postreduction radiography would then be restricted to patients with either a clinically significant fracture found on initial radiography, or an uncertain reduction. The predictive accuracy of this rule for clinically important fractures associated with a shoulder dislocation is reported in Table 3. Applying this rule would decrease the number of prereduction radiographs by $27.9 \%$ (62/222) and postreduction radiographs by $81.9 \%(182 / 222)$ without missing any clinically important fracture-dislocations. The median time to obtain a prereduction radiograph was 26.5 (interquartile range 9.6-96.6) minutes.

Further exploration of the CART analysis revealed that "having a first episode" dichotomized node 4 in Figure 1 and was of borderline predictive significance (improvement $=0.001)$. In younger patients with concerning mechanisms of injury, restricting radiography to patients with no previous dislocation would improve specificity, but would do so at the expense of 1 missed significant fracture. Specifically, using this more restrictive rule would have led to a $38.7 \%(86 / 222)$ decrease of prereduction radiographs with a sensitivity of 97.5 (39/40) (95\% CI 87.1-99.9), a specificity of 46.7 (95\% CI 39.6-53.9), a positive predictive value of 28.7 (95\% CI 21.7-36.8) and a negative predictive value of 98.8 (95\% CI 93.7-99.9).

\section{Discussion}

To our knowledge, this is the largest prospective study on clinical predictors of fractures associated with anterior glenohumeral dislocation, and refines our previous retrospective study. ${ }^{6}$ Some authors have argued that our outcome is debatable; clinically important fracture-dislocation may or may not need to be identified before reduction from a patient care point of view., ${ }^{3,6,17,18}$ In 2003, Perron and colleagues $^{19}$ showed that all shoulder dislocations in a retrospective cohort of patients who were seen in a single academic centre were reduced in the ED. However, this review did suffer from systematic data collection and incomplete radiographic evaluations, while missing important injuries. Moreover, this study may lack generalizabilty. 
The proportion of Hill-Sachs lesions was $76 \%$ of all fracture-dislocations, which is greater than other cohort studies. ${ }^{6,910}$ For the current study and our prior derivation phase, ${ }^{6}$ we used clinically important fracture dislocations that would require special attention during the reduction as well as orthopedic follow-up, as suggested by Hersche and Gerber. ${ }^{20}$ Most clinicians would argue that a clinically important fracture-dislocation should be identified before any attempt at reduction. Nevertheless, we encountered 2 patients (each decision-rule positive) in which such fractures were not identified despite prereduction radiography. Allowing clinicians to obtain postreduction radiographs in a limited number of cases based on clinical unease appears to be both sensible and useful for identifying such cases

Three studies have described risk factors associated with either recurrence or complications of anterior shoulder dislocations without associated fractures. ${ }^{4,14,21}$ In a descriptive review, Rowe ${ }^{22}$ reported that patients with fracture-dislocations were older on average. The use of 40 years of age as a cut-off is consistent with prior case series $^{4,5}$ and our previous work. ${ }^{6}$
It is noteworthy that humeral ecchymosis is the only physical finding predictive of a fracture-dislocation, in contrast with our previous work. ${ }^{6}$ Although this clinical sign is likely time-dependent and could be easily overlooked, its early presence may signal higher energy of injury, and is associated with humeral fracture. ${ }^{23}$

A patient's first glenohumeral dislocation represents an important predictor of fracture, especially in older patients. Hendey and coworkers ${ }^{9}$ advocate forgoing radiography in patients who experience recurrent dislocations with an atraumatic injury.

Two studies have reported that being male or under the influence of alcohol increases the risk of shoulder dislocation. ${ }^{2,24}$ Although our unadjusted univariate analysis initially suggested relationship between the presence of fracture-dislocation and sex, this factor was rejected in our final model. The presence of alcohol intoxication was not associated with the presence of a clinically important fracture-dislocation.

The mechanism of injury remains an important predictor of fractures. ${ }^{25}$ Hendey and coauthors ${ }^{9}$ also recommend

\begin{tabular}{|c|c|c|c|c|c|}
\hline \multirow[b]{2}{*}{ Predictor } & \multicolumn{4}{|c|}{ Group, no. (\%) } & \multirow[b]{2}{*}{$p$ value } \\
\hline & \multicolumn{2}{|c|}{$\begin{array}{l}\text { Clinically important } \\
\text { fracture-dislocation, } \\
\qquad n=40\end{array}$} & \multicolumn{2}{|c|}{$\begin{array}{c}\text { Uncomplicated } \\
\text { dislocation, } n=182\end{array}$} & \\
\hline Age $\geq 40 \mathrm{yr}$ & 35 & $(87.5)$ & 75 & $(41.2)$ & $<0.001$ \\
\hline Female sex & 19 & $(47.5)$ & 47 & $(25.8)$ & 0.007 \\
\hline Alcohol intoxication & 6 & $(15.0)$ & 20 & (10.9) & NS \\
\hline \multicolumn{6}{|l|}{ Side affected } \\
\hline Right & 23 & $(57.5)$ & 97 & $(53.2)$ & NS \\
\hline First episode & 27 & $(67.5)$ & 83 & $(45.6)$ & 0.007 \\
\hline \multicolumn{6}{|l|}{ Injury mechanism } \\
\hline Atraumatic & 1 & (2.5) & 41 & $(22.5)$ & 0.032 \\
\hline \multicolumn{6}{|l|}{ Falls } \\
\hline Patient's own height & 18 & $(45.0)$ & 46 & $(25.2)$ & 0.006 \\
\hline$<1$ flight of stairs & 6 & $(15.0)$ & 19 & $(10.4)$ & NS \\
\hline$>1$ flight of stairs & 1 & $(2.5)$ & 2 & $(1.1)$ & NS \\
\hline \multicolumn{6}{|l|}{ Sports activity } \\
\hline With speed & 2 & $(5.0)$ & 23 & $(12.6)$ & NS \\
\hline With contact & 8 & $(20.0)$ & 39 & $(21.4)$ & NS \\
\hline Fight or assault & 1 & $(2.5)$ & 3 & $(1.6)$ & NS \\
\hline MVC & 3 & $(7.5)$ & 9 & $(4.9)$ & NS \\
\hline $\begin{array}{l}\text { Humeral head palpated outside the } \\
\text { glenoid cavity }\end{array}$ & 26 & $(65.0)$ & 157 & $(86.2)$ & NS \\
\hline Presence of bone crepitant & 0 & $(0.0)$ & 0 & $(0.0)$ & - \\
\hline Presence of humeral ecchymosis & 5 & $(12.5)$ & 4 & $(2.2)$ & 0.001 \\
\hline Presence of parasthesia or hyposthesia & 4 & $(10.0)$ & 24 & $(13.2)$ & NS \\
\hline Presence of vascular abnormalities & 0 & $(0.0)$ & 0 & $(0.0)$ & - \\
\hline
\end{tabular}


prereduction radiography for all patients with traumatic dislocation. Our results partially support these recommendations. Indeed, no clinically important fracture-dislocation occurred in young patients with an atraumatic dislocation or a fall from their own height or less. Our study differs from Hendey and coauthors' in that their rule recommends prereduction radiography for all first-time shoulder dislocations and for any significant blunt trauma, including a fall from one's own height. Our rule is more selective and does not recommend prereduction radiography for patients under 40 with a first-time dislocation or ground-level fall.

In 2006, Hendey and colleagues ${ }^{9}$ proposed an algorithm for the management of patients with suspected shoulder dislocation that lowered the number of prereduction radiographs by $36 \%$. We encountered fewer patients $(11.6 \%$ compared with $39.0 \%$ ) with recurrent dislocations and an atraumatic mechanism. This difference could be partly explained by our enrolling patients only once, thereby underrepresenting recurrent dislocations. Patients in the study by

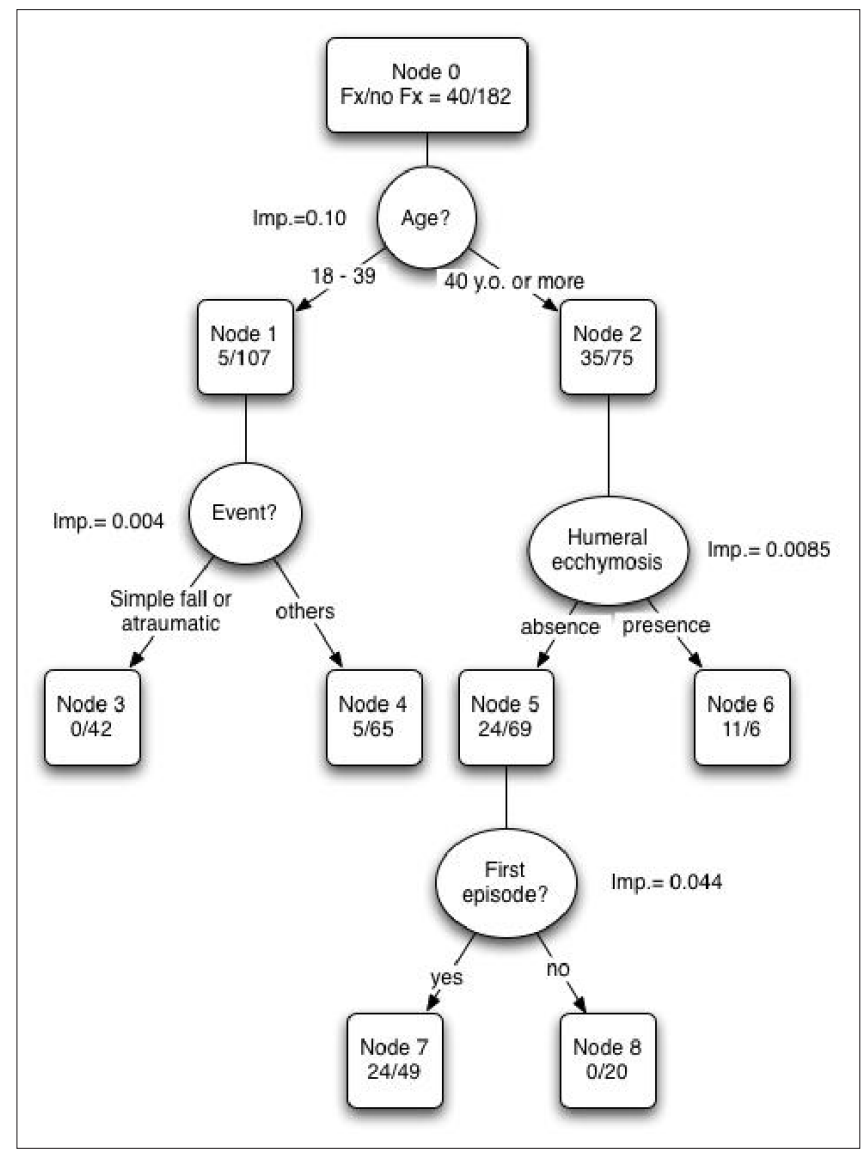

Fig. 1. Classification and regression tree (CART) analysis for prereduction radiography. Clinically important fracturedislocation/noncomplicated ratio ( $\mathrm{Fx} / \mathrm{no} \mathrm{Fx}$ ) is shown for each node. Improvement (Imp.) results of CART analysis are shown.
Hendey and colleagues were younger with a higher proportion of recurrent dislocations than had been previously reported. ${ }^{1,6,10}$ Hendey and coworkers' algorithm should be subject to further validation in a different population before widespread use.

With regard to postreduction radiographs, Hendey and colleagues' algorithm reportedly reduced these by $41 \%$.

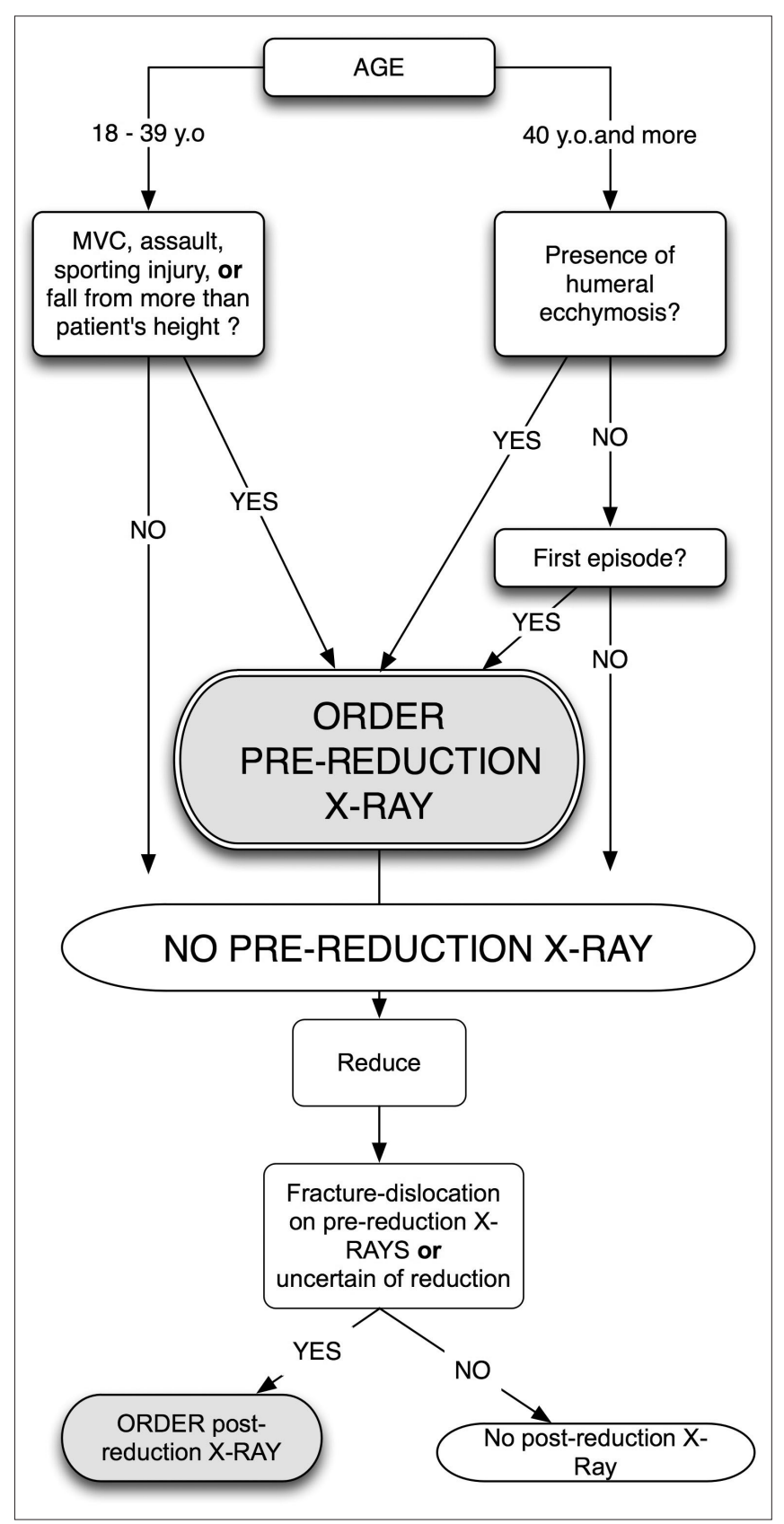

Fig. 2. The Quebec shoulder dislocation rule. For patients with an acute anterior shoulder dislocation who are alert (as indicated by a score of 15 on the Glasgow Coma Scale) and in stable condition. Note: A fall from patient's own height excludes any sporting injuries. 
Applying Hendey and coworkers' algorithm to our data resulted in a reduction in postreduction radiography in 195 patients $(83.1 \%)$, based on reduction being considered successful by the EP. These results validate the observations by both Harvey and colleagues ${ }^{7}$ and Hendey and Kinlaw $^{12}$ that postreduction radiography rarely reveals any clinically significant abnormality after an anterior shoulder dislocation has been reduced.

The Quebec shoulder dislocation rule had 100\% sensitivity for identifying clinically important fracture-dislocations. Applying these criteria would still allow physicians to identify patients with significant injuries relevant to acute management. Our model seems to perform better than physician judgment, previously found to be only $77 \%$ sensitive $^{6}$ and permits more judicious use of radiography. Use of this rule could decrease radiation exposure, decrease use of ED equipment and services, and, as already reported, reduce the length of ED stay. ${ }^{10}$ Future validation of the Quebec rule for both pre- and postreduction radiography would lead to more efficient care of acute anterior shoulder dislocation patients in the ED.

\section{Limitations}

Our study has several limitations. First, we did not evaluate interobserver agreement of our predictive factors. Our research ethics board deemed it inappropriate to delay care of this painful, urgent orthopedic condition. However, most of the variables in our clinical decision rule required little subjective interpretation (age, first episode, mechanism of injury) and would be expected to have good interobserver agreement, as corroborated by another derivation study. ${ }^{26}$ Interobserver agreement will need to be addressed in a future validation study.

\begin{tabular}{lcc}
$\begin{array}{l}\text { Table 3. The ability of the Quebec shoulder dislocation rule } \\
\text { to predict the presence of clinically important fractures on } \\
\text { radiography }\end{array}$ & \multicolumn{2}{c}{$\begin{array}{r}\text { Clinically important fracture- } \\
\text { dislocations }\end{array}$} \\
\cline { 2 - 3 } $\begin{array}{l}\text { Prereduction radiography } \\
\text { suggested }\end{array}$ & Yes & No \\
\hline Yes & 40 & 120 \\
No & 0 & 62 \\
\hline Prediction ability & Ratio & $95 \% \mathrm{Cl}$ \\
\hline Sensitivity & 100.0 & $89.4-100.0$ \\
Specificity & 34.2 & $27.7-41.2$ \\
PPV & 25.2 & $19.1-32.4$ \\
NPV & 99.2 & $92.8-99.9$ \\
LR + & 1.5 & $1.34-1.68$ \\
LR - & 0.04 & $0.002-0.27$ \\
\hline
\end{tabular}

$\mathrm{Cl}=$ confidence interval; $\mathrm{LR}=$ likelihood ratio; $\mathrm{NPV}=$ negative predictive value; PPV $=$ positive predictive value
The prevalence of fracture-dislocations observed in this study was intermediate relative to previously published data. ${ }^{12,15}$ Of the 4 recruitment centres, only 2 were designated trauma centres.

Also we only addressed the issue of whether or not a clinically important fracture was present, not whether physicians could clinically identify a glenohumeral dislocation. Uncertainty regarding the diagnosis of dislocation would lead to radiography, irrespective of the rule. On the other hand, postreduction radiography management appears intuitive and is consistent with a previous publication. ${ }^{9}$ Thus a substantial reduction in radiography seems probable overall.

\section{Conclusion}

We improved, confirmed and refined our previously derived set of predictive factors for rationalization of radiography in acute shoulder dislocation in the ED. The resultant Quebec shoulder dislocation rule achieved a sensitivity of $100 \%$. Application of the rule could decrease the use of prereduction radiography by nearly $30 \%$ and postreduction radiography by more than $80 \%$ without missing clinically significant fracture-dislocations. Further validation of this rule in different population settings is warranted.

Acknowledgments: The authors acknowledge Dr. Gregory W. Hendey, faculty research director, University of California, Fresno, for critical reading and constructive discussion of the manuscript. In addition, we thank our research assistant, Pierre Provencher, for his dedicated time, and all the emergency physicians who participated in this study.

\section{Competing interests: None declared.}

Funding provided by the Canadian Association of Emergency Physician Research Grant, L'Association des médecins d'urgence du Québec and from le Programme National de Recherche en Traumatologie du Fonds de recherche en Santé du Québec (015102).

Preliminary results from this paper were presented at the annual meeting of the Association des médecins d'urgence du Québec, Québec City, Que., November 2006.

\section{References}

1. Kroner K, Lind T, Jensen J. The epidemiology of shoulder dislocations. Arch Orthop Trauma Surg 1989;108:288-90.

2. Nordqvist A, Petersson CJ. Incidence and causes of shoulder girdle injuries in an urban population. J Shoulder Elbow Surg 1995;4:107-12.

3. Mohamud D. Shoulder, in Rosens's Emergency Medicine: concepts and clinical practice, J. Marx, editor. St. Louis. (MO): Mosby; 2002. p. 576-606. 
4. Cleeman E, Flatow EL. Shoulder dislocations in the young patient. Orthop Clin North Am 2000;31:217-29.

5. Stayner LR, Cummings J, Andersen J, et al. Shoulder dislocations in patients older than 40 years of age. Orthop Clin North Am 2000;31:231-9.

6. Émond M, Le Sage N, Lavoie A, et al. Clinical factors predicting fractures associated with an anterior shoulder dislocation. Acad Emerg Med 2004;11:853-8.

7. Harvey RA, Trabulsy ME, Roe L. Are postreduction anteroposterior and scapular Y views useful in anterior shoulder dislocations? Am J Emerg Med 1992;10:149-51.

8. Hendey GW. Necessity of radiographs in the emergency department management of shoulder dislocations. Ann Emerg Med 2000;36:108-13.

9. Hendey GW, Chally MK, Stewart VB. Selective radiography in 100 patients with suspected shoulder dislocation. J Emerg Med 2006;31:23-8.

10. Shuster M, Abu-Laban RB, Boyd J, et al. Prospective evaluation of a guideline for the selective elimination of pre-reduction radiographs in clinically obvious anterior shoulder dislocation. CJEM 2002:4:257-62.

11. Shuster M, Abu-Laban RB, Boyd J. Prereduction radiographs in clinically evident anterior shoulder dislocation. Am J Emerg Med 1999;17:653-8.

12. Hendey GW, Kinlaw K. Clinically significant abnormalities in postreduction radiographs after anterior shoulder dislocation. Ann Emerg Med 1996;28:399-402.

13. Anis AH, Stiell IG, Stewart DG, et al. Cost-effectiveness analysis of the Ottawa Ankle Rules. Ann Emerg Med 1995;26: 422-8.

14. Taylor DC, Arciero RA. Pathologic changes associated with shoulder dislocations. Arthroscopic and physical examination findings in first-time, traumatic anterior dislocations. Am J Sports Med 1997;25:306-11.

15. Breiman L. Classification and regression trees. Wadsworth statistics/probability series. New York (NY): Chapman and Hall;1993. p. 358.

16. Carley S, Dosman S, Jones SR, et al. Simple nomograms to calculate sample size in diagnostic studies. Emerg Med J 2005;22:180-1.

17. Beeson MS. Complications of shoulder dislocation. Am J Emerg Med 1999;17:288-95.

18. Blake R, Hoffman J. Emergency department evaluation and treatment of the shoulder and humerus. Emerg Med Clin North Am 1999;17:859-76.

19. Perron AD, Ingerski MS, Brady WJ, et al. Acute complications associated with shoulder dislocation at an academic emergency department. J Emerg Med 2003;24:141-5.

20. Hersche O, Gerber C. Iatrogenic displacement of fracture-1 dislocations of the shoulder. A report of seven cases. J Bone Joint Surg Br 1994;76:30-3.

21. Pasila M, Jaroma H, Kiviluoto O, et al. Early complications of primary shoulder dislocations. Acta Orthop Scand 1978;49:260-3.

22. Rowe CR. Prognosis in dislocations of the shoulder. J Bone Joint Surg Am 1956;38-A:957-77.

23. Lind T, Kroner K, Jensen J. The epidemiology of fractures of the proximal humerus. Arch Orthop Trauma Surg 1989;108:285-7.

24. Nordqvist A, Petersson CJ. Shoulder injuries common in alcoholics. Analysis of 413 injuries. Acta Orthop Scand 1996;67: 364-6.

25. Pasila M, Kiviluoto O, Jaroma $\mathrm{H}$, et al. Recovery from primary shoulder dislocation and its complications. Acta Orthop Scand 1980;51:257-62.

26. Stiell IG, Wells GA, Vandemheen K, et al. The Canadian CT Head Rule for patients with minor head injury. Lancet 2001 ; 357:1391-6.

Correspondence to: Dr. Marcel Émond, Unité de recherche en traumatologie, urgence et soins intensifs, Centre Hospitalier Affilié, Site Enfant-Jésus, 1401, rue 18eme, Québec City QC G1J 1Z4; marcelemond@hotmail.com 